\title{
Calotropis boon or bane?
}

\author{
Vibha Singh \\ Chhatrapati Shahuji Maharaj Medical University, Lucknow, India \\ Email: drvibha66@yahoo.com, vibhasinghraghuvanshi@gmail.com \\ Received 15 February 2012; revised 15 March 2012; accepted 26 March 2012
}

\begin{abstract}
The herbal medicine occupy distinct position right from ancient period. The plant Calotorpis procera is known by different name in different part of world like French cotton, Alarka, or Madar, Rooster tree, and Widuri. The plant is poisonous can lead to blindness if its juice is put in to the eyes. The same plant is used for Ayurvedic medicines. The medicinal properties like Calotropin isolated from latex is used as remedy for painful tooth cavities rheumatism, syphilis, leprosy and edema, for ring worm, syphilitic soreness, and leprosy cutanous dryness and toothache. Latex is al so used in the treatment of gum bleeding and as odontagic. Flowers can all so be used for toothache, and ringworm infection. As the adage goes excess leads to distress, the judicious use of herbal medication is recommended otherwise it will lead to complication, as described in the case report.
\end{abstract}

Keywords: Calotropin, Anti-Inflammatory, Oroantral Communication

\section{INTRODUCTION}

The herbal medicine occupy distinct position right from ancient period. Arka (calotropis procera) an important drug of Ayurveda is known in India from the earliest time. It is mentioned by the earliest Hindu writers and the ancient name of the plant which occurs in Vedic literature was Arka alluding to the form of leaves which was used in sacrificial rites [1] The ethnobotanical pharmacology is as old as man himself. The plant Calotorpis procera is known by different name in different part of world like French cotton, Alarka, or Madar, Rooster tree, and Widuri. Calotorpis procera in India holds a pride of place largely because of its other uses and economic values. The Aak is wild plant which is commonly found in India. The genus Calotropis R.Br. (Asclepiadaceous) is distributed in tropical and sub-tropical regions of Asia and Africa. It is represented in India by two species viz. C. procera and C. gigantean. There is no difference except colors of the flowers. It is small medium size shrub that is white in earlier one and pinkish white in the second one. It has exceptional medicinal value. In Dhanvantari Nigantu three varieties of Arka are mentioned viz Rajarkah, Suklarkah and Sveta mandarah. It has widely used in the Sudanese, Unani, Arabic and Indian Traditional medicinal system for the treatment of various diseases namely leprosy, ulcers, piles and diseases of spleen, liver and abdomen. The latex is used as an abortifacient spasmogenic and carminative properties antidysentric, antisyphilitic, antirheumatic, antifungal, mullusccide, diaphoretic and for the treatment of leprosy, bronchial asthma, and skin affiction [1]. The plant is poisonous can lead to blindness if its juice is put in to the eyes. The same plant is used for Ayurvedic medicines. It has cardio active steroids. These medicines have fewer side effects. India being a tropical country is blessed with vast natural resources and ancient knowledge for its judicious utilization.

\section{CASE REPORT}

A 35 years old lady reported to the department of oral and Maxillo facial surgery with the complaint of pain, swelling and regurgitation of food and fluid from nose for 7 days. She had toothache in right upper posterior carious molar, thus she applied cotton pack wet with latex of the Calotropis which resulted in the burning of the mucosa, inflammation and formation of oro antral communication (Figure 1).

On examination there was slough on the palate with the oro antral communication with inflammation. Irrigation was done with normal saline. It was advised that she should be carried out irrigation with warm saline gargle and with povidon iodine solution. The antibiotic and anti-inflammatory drugs were prescribed for 7 days .The radiograph OPG view revealed carious broken upper molar along with root stumps of $2^{\text {nd }}$ and $3^{\text {rd }}$ molar (Figure 2). The occipitomental view revealed haziness of the right maxillary sinus (Figure 3). The upper molar and root stumps were extracted simultaneously closure of the communication was done with buccal pad of fat. Post operative healing was uneventful (Figure 4). The Figures 5 and 6 showing C. procera plant and flower. 


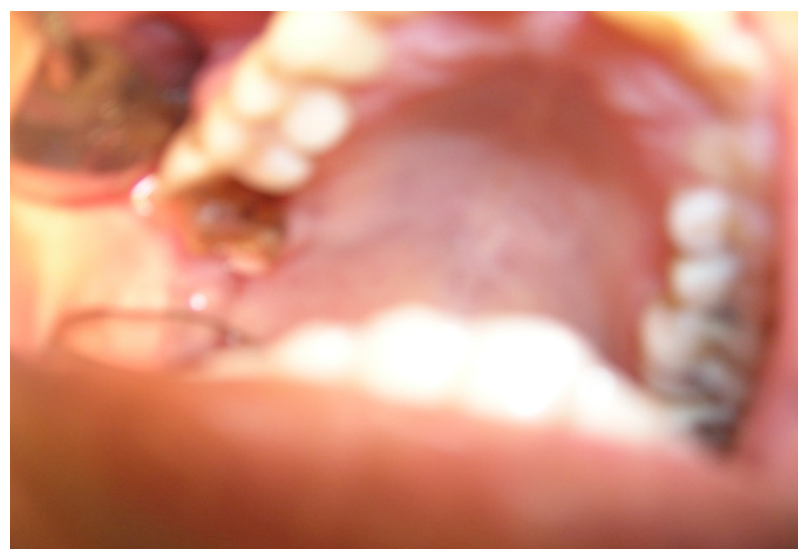

Figure 1. Injury caused by latex of $C$. procera.

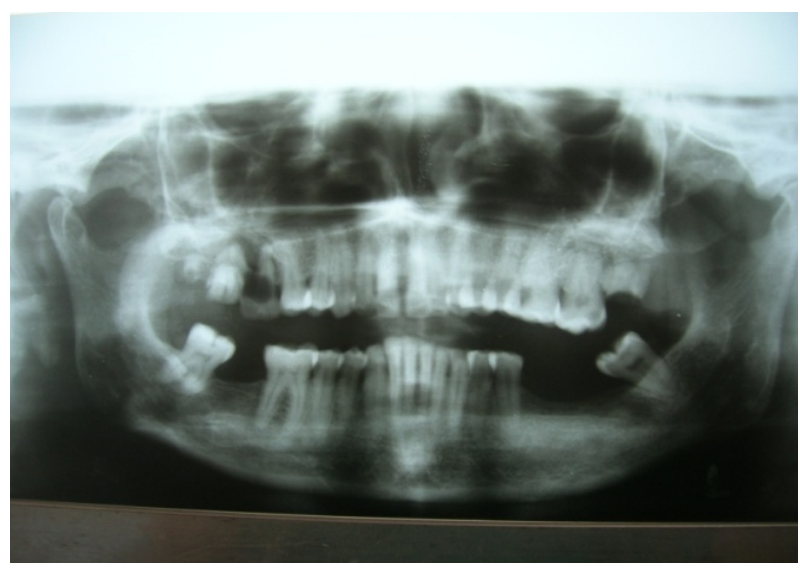

Figure 2. Orthopentogram view.

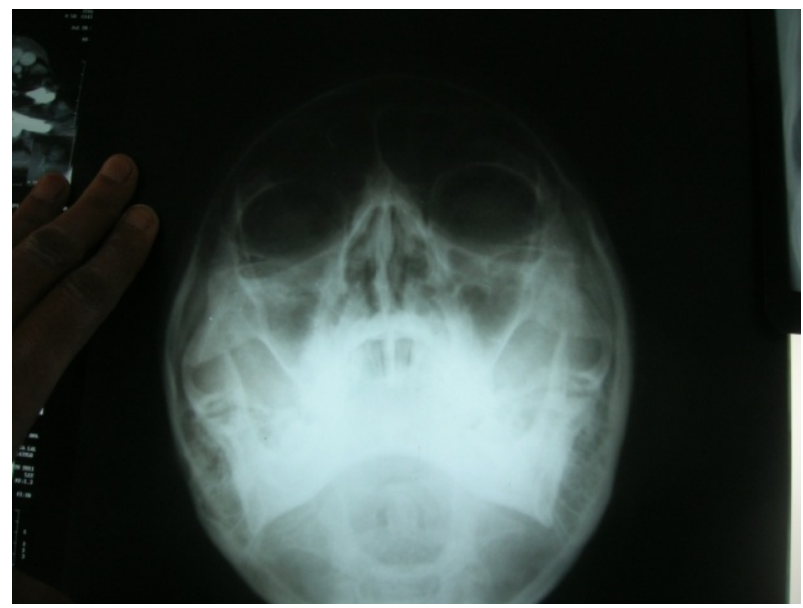

Figure 3. Occipitomental view.

\section{DISCUSSION}

The medicinal properties like Calotropin isolated from latex is used as remedy for painful tooth cavities rheumatism, syphilis, leprosy and edema. (Kew, 1985), for ring worm, syphilitic soreness, and leprosy cutanous dryness (Pandey and Aneeta, 1990) for toothache Galav

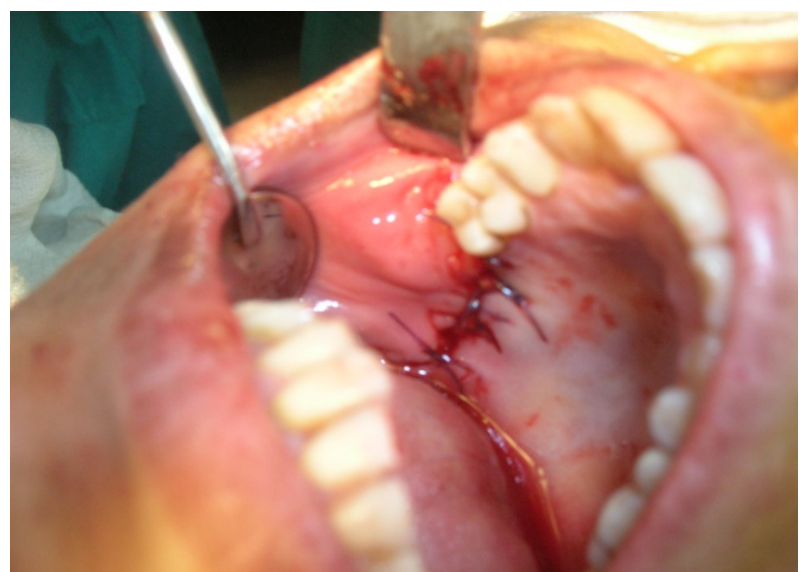

Figure 4. Post operative.

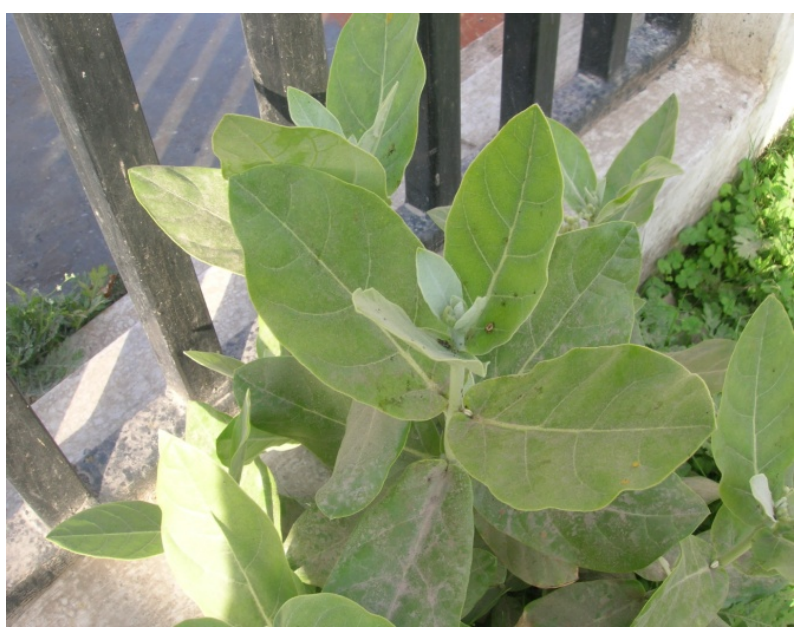

Figure 5. Calotropis procera plant.

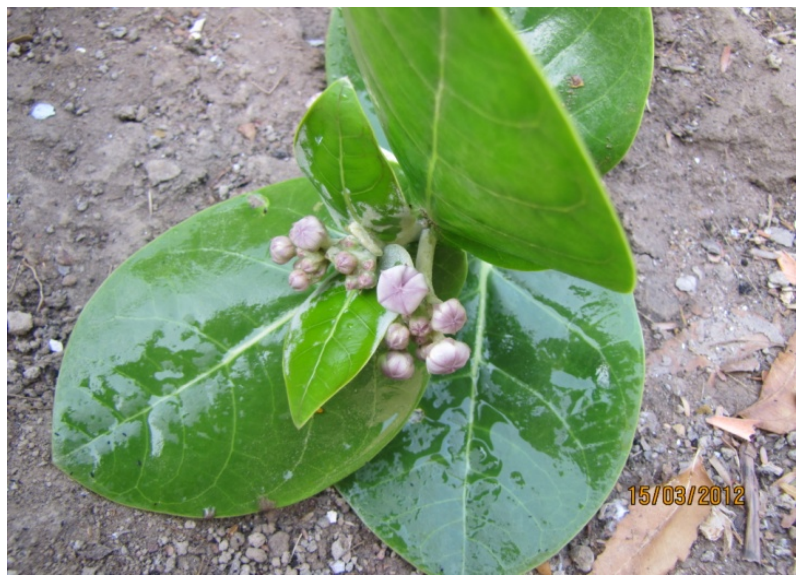

Figure 6. Flowers of Calotropis procera.

et al. (2007). Latex is al so used in the treatment of gum bleeding, (showkat) 2007 and as odontagic (patil et al. 2009). Flowers can all so be used for toothache, and ringworm infection (Shati et al. 2009). The antibacterial activities of the $C$. procera against bacteria and fungi 
have been reported [1]. The level of hydroproline hexosamine, uronic acid DNA, RNA and protein in the wound matrix revealed pro healing effect of the latex [2].

The anti-inflammatory properties of the flowers, root and latex are reported. It is due to its ability to inhibit histamine and bradykinine and partially inhibiting prostaglandin E2. It is al so reported that the active anti-inflammatory compound to be protein in nature so inhibitory effect of the latex is likely to be cell mediated [3]. The root bark is excellent mechanism for colic and stomach problem, asthma is treated by using either flowers or the root in decoction. It is popularly used to treat leprosy in Africa. There are other uses in other part of the world like for the snake bite, hypermenorrhoea.

The Calotropis procera al so have antimicrobial effect, the ethanol, aqueous and choloform extract of leaf and latex of C. procera on E. coli, Staphylococcus aureus, Streptococcus pyogenes, Streptococcus pneumonia and fungi Aspergillus niger, A. flavus, Microsporium boulardii and yeast Candida albicans were determined. The C procera latex demonstrated strong inhibitory effect on these organism.

However, in order to make these remedies acceptable to modern medicine, there is a need to scientifically evaluate them, to identify the active principles and to understand the mechanism of action (Ashok Vaidya, 1998) [4].

The Nubians made use of the latex to cure toothache and loosen tooth to facilitate extraction. There are in some areas roots are used as tooth brush to prevent and cure toothache. It all so has analgesic and antipyretic activities. Its chloroform fractions root extract showed anti ulcer, indomethacin, and in stress induced ulceration [5].

The chemical, Akundaric acid, akundrol, akundarol isovalerate, calotropin,caoutchouc, madaralbum, madarfluvil, mudaric acid, mudarine, mudarol isovalerate, mudrol, pekilocerin A, Silver salt, uscharidin, uzarigenin, uzarigenin 3-0, (b-d-glucopyranosyl-(-1>2)-b-D-glucopyranoside), voruscharin, are present in the plant. The latex has direct irritant effect on the mucous membrane particularly in the eye.

Skin irritation of this plant may be caused by allergy rather than to a direct irritant action. All the part of the plant contains a cardio active steroid and calcium oxalate crystals, and cardio steroid resembling digitalis. Human intoxication from plant has been reported in modern times. Ingestion of the calcium oxalate causes painful burning sensation of the lip tongue, and mouth. There is inflammatory reaction often edema and blistering, hoarseness, dysphasia, and dysphonia may result. Poisoning would be expected to produce clinical findings typical of cardio active steroids. Toxicity has variable latent periods depends on the quantity ingested, Sinus bradycardia, premature ventricular contraction, A-V conduction defect or ventricular tachycardia, dysarrthymias, hypercalmia, if present may be present as an indicator of toxicity. Calcium oxalate toxicity, pain edema, recedes slowly without therapy, cool liquid or demulcents held in mouth may bring some relief. Analgesics and antibiotics may be given .The insoluble oxalate in the plant does not cause systemic poisoning. The $C$. procera species induced keratiatis is reported by number of workers. Some studies al so reported wound healing potential of C. gigantean in animal studies. The clinical picture of the keratiatis includes the painless dimness of vision with photophobia, conjunctival conjection, and mild to severe corneal edema. This could lead to epithelial defect iridocylitis and secondary glaucoma as complication. The toxicity is reversible provided latex did not penetrate the corneal stroma and induced permanent loss of endothelial cells. Treatment with local steroid drops seems to be best way of healing [6].

The management of this type of lesion requires removal of offending agents and systemic therapy. In case of self inflicted injury it might be difficult patients to stop the noxious behavior, irrigation is the treatment of choice to minimize the product effect immediately. If patient reports 2, 3 day after injury with the complain of pain, debridement of the wound irrigation and local dressing with topical analgesic and antibacterial ointments along with systemic analgesic and antibiotics should be prescribed.

The hazardous effects of the calotropis, the milky exudates from the plant is a corrosive. It is said to have mercury like effects on the human body and is sometimes referred as vegetable mercury. Calotropin a compound in the latex is more toxic than strychnine which are responsible for the cytotoxicity of Apocynum cannabinum [7].

The milky latex contains a powerful bacteriolytic enzyme, toxic glycoside calactin, calotropin D1, calotropin D2 calotropin F11, and a nontoxic powerful proteolytic enzyme. Latex of calotropis exhibited local anesthetic activity [10].

The ocular toxicity following accidental inoculation of latex of calotropis procera is reported. All the patients presented with sudden painless dimness of the vision with photophobia. The alkaloids of the latex are caustic and considered poisonous in nature. Accidental contact of the calotropis latex in to eye causes violent keratoconjunctivitis with associated corneal edema and gross diminish of vision without any pain.

As the adage goes excess leads to distress, the judious use of herbal medication is recommended otherwise it will lead to complication, as described in the above 
case.

\section{REFERENCES}

[1] Calotropis giantea (2012). http://en.wikipedia.org/w/index.php

[2] Saratha, V., Subramanian, S. and Sivakumar, S. (2010) Evaluation of wound healing potential of Calotropis gigantean latex studied on excision wounds in experimental rats. Medicinal Chemistry Research, 19, 936-947. doi:10.1007/s00044-009-9240-6

[3] Kareem, S.O., Akpan, I. and Ojo, O.P. (2008) Antimicrobial activities of Calotropis procera on selected pathogenic microorganism. African journal of Biomedical Research, 11, 105-110.

[4] Sahgal, R. and Kumar, V.L. (2005) Calotropis procera latex induced inflammatory hyperalgesia-Effect of anti inflammatory drugs. Mediators of Inflammation, 31, 216220.

[5] Global information Hub on Integrated Medicine.

[6] Dewan, S., Sangraula, H., Kumar, V.L. (2009) Preliminary studies on analgesic activitiy of latex of Caltropis procera. Journal of Ethnopharmacology, 73, 307-311. doi:10.1016/S0378-8741(00)00272-5

[7] Pathyusha, R.J.B. (2012) Potential of local anesthetic activity of calotropis procera latex with epinephrine and $\mathrm{pH}$ in guinea pig. http//www.pharmatutor.org/articles/Pharmatutor-art-1043

[8] Samar, K.B., Arup, B., Ayan, M. and Prashant, S. (2009) Oculatr toxicity by latex of Calotropis procera. Indian Journal of Ophthalmology, 57, 232-234. doi:10.4103/0301-4738.49402 